\title{
3. Individual decision-making in a social context: the sociological determinants of female sports participation Judith Stull
}

\subsection{INTRODUCTION}

In the fall of 2011, Pinckney Community High School experienced the most unusual homecoming football game in its history. Barely an hour after being crowned homecoming queen, Pinckney senior Brianna Amat kicked the winning field goal in a 9-7 victory over rival Grand Blanc High School (Maynard, 2011). At halftime, Brianna appeared on the field with her court. The courtiers were dressed in long gowns, while the queen appeared in her football uniform. For one evening, at least, Ms Amat and the community in which she lived were able to bridge the worlds of femininity and athleticism.

Unfortunately, while such accounts are inspiring for many, they are relatively rare. Girls and women still need to navigate conflicting social expectations. Among the ways in which girls and women 'get to understand their roles' is through parental expectations, peer pressure, and the media. Indeed, girls and women are not only the object of these pressures; they in turn participate in their enforcement as well.

Female athletes are particularly subject to societal pressure because of cultural lag. The concept of cultural lag was first developed by William Ogburn (1922) and later elaborated by Woodard (1934). Ogburn saw cultural lag as the result of conflict between a society's material and nonmaterial culture. At some risk of oversimplification, material culture refers to the physical resources that help provide a collection of individuals with a unifying identity. The material culture of the United States includes objects ranging from shopping malls and houses of worship to i-pads. Non-material culture consists of the ideas, belief structures, and institutions that help those individuals provide meaning to their physical resources. Cultural lag exists because the material culture typically changes and evolves more quickly than the non-material culture. When this occurs, people change their behavior more quickly than they change their ideas as to what is right or appropriate.

Cultural lag results in a period of conflict or maladjustment at the 
individual level when individuals obtain objects or engage in activities that they feel are somehow wrong. It is reflected at the social level when one portion of a group tries to repress the behaviors of another. This conflict between material goods and beliefs was popularized in Thomas Friedman's The Lexis and the Olive Tree (Friedman, 2000). A similar conflict is currently occurring with respect to girls' and women's participation in sports and exercise. While this conflict occurs throughout the world, it expresses itself in different ways and with different intensities in different societies.

This chapter explores the cultural conflicts that have accompanied the growing participation of women in organized sport and physical activity. In Section 3.2, I present sociological concepts to analyze the problems faced by female athletes. Because this volume is intended for economists, many of whom have little or no background in sociology, I provide background and define terms that are unfamiliar to economists. In Section 3.3, I apply these tools to the issue of conforming to a socially desired body image, which is a general problem that women confront. In Section 3.4, I use the concepts from Sections 3.2 and 3.3 to explain the pressures faced by female athletes in the United States and other Western cultures, especially those competing at the elite level. In Section 3.5, I turn to the conflict surrounding women who wish to participate in sports in an Islamic society or in an Islamic subgroup of a Western society. Section 3.6 concludes.

\subsection{THEORETICAL PERSPECTIVE: ROLES AND STATUSES}

To put this discussion in context it is necessary to understand how an individual's life is structured and how it functions. First, expectations as to appropriate attitudes and behaviors are complex and evolving. At any one moment in time, a person participates in many social groups, such as family, friends, and co-religionists. Each of these groups can affect that person by imposing explicit and implicit expectations. The individual's behavior can, in turn, affect the larger system. The constant interplay between the group and its individual members thus forms a dynamic process.

Individuals have differing time and emotional commitments to the groups to which they belong. Some of these commitments reinforce one another, while others conflict. Figure 3.1 illustrates the nature of these commitments. The largest circle in the figure represents the society within which an individual functions. The smaller circles are of varying size and represent subcultures within the larger culture. As noted earlier, some of 


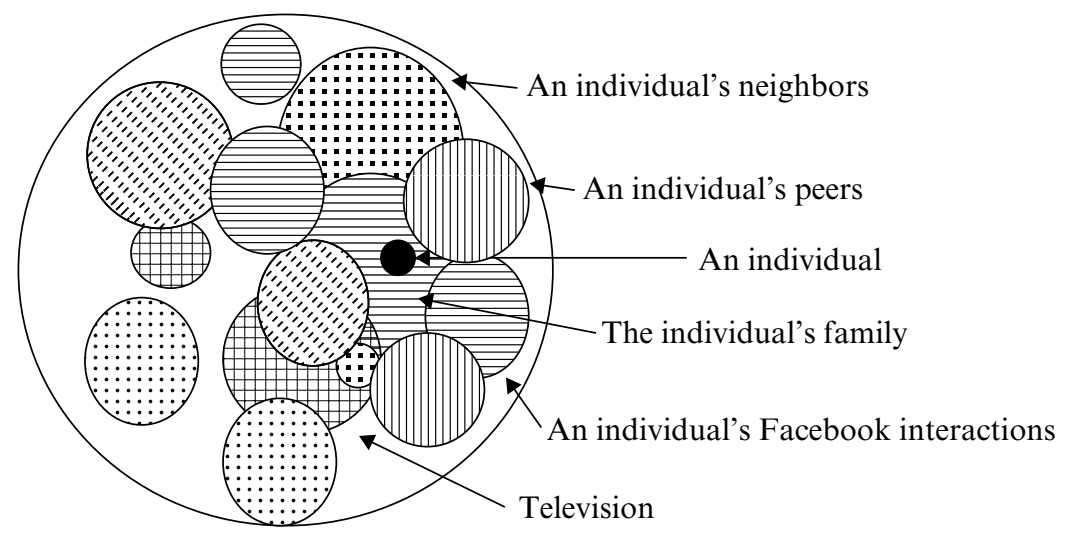

Figure 3.1 Representation of some of an individual's status/role obligations

these subcultures overlap one another. In fact, some subcultures might be entirely contained within larger subcultures. Being necessarily static in nature, the figure fails to capture the dynamics of the system. In reality, the circles continually grow, shrink, and move relative to one another, reflecting the interaction of the components of the umbrella culture with one another and with the umbrella culture as a whole.

The two basic dimensions of social behavior are the content of the culture and the structure of the culture. Values and norms define a culture's content. Values are the theoretical and emotional underpinnings of a culture. Unfortunately, they are difficult to measure. While individuals may hold on very strongly to their value systems, they frequently are reluctant or unable to reveal or explain them to outsiders. For example, they might respond as they think the researcher desires or expects them to respond. This can be a particularly acute problem when studying youth sports, as the subject is frequently a student who is responding to a faculty member (see, for example, Walseth and Fasting, 2003; Walseth, 2006). Indeed, Garfinkel (1984) claims that people reveal their values only by violating them. Norms, the rules of social behavior, run the gamut from folkways that informally regulate everyday social encounters to rigidly enforced religious or secular laws. Unlike values, norms can be measured by observing people's behavior because people's behaviors reflect their norms.

The structure of a culture is determined by statuses and roles. At any one point in time, individuals hold many 'statuses', that is positions, in their social lives. Some of these statuses are ascribed to the individuals, as they 
neither created them nor volunteered to hold them. Examples of ascribed statuses are 'woman', 'daughter', or 'Asian'. Other statuses are achieved in that the individual had to do something to attain them. Examples of achieved statuses are 'athlete', 'college graduate', or 'accountant'. Thus, because Elizabeth II became Queen of England because she was the firstborn child of King George VI, her position as queen is an ascribed status. In contrast, Barack Obama's position as President of the United States is an achieved status because he successfully sought election to the post. An individual's menu of statuses changes over time, as is the case with age, which progresses through infancy, early childhood, middle childhood, adolescence, and adulthood.

A role is associated with each status that an individual holds. A role is composed of the rights and responsibilities that attach to a specific status. Roles therefore dictate how an individual behaves. Charles Cooley (1902) and later Crosnoe and Muller (2004) explained that an individual learns the appropriate behaviors associated with a role by appealing to what they call the 'Looking-Glass Self Model'. In this model, individuals internalize societal roles in order to meet with approval:

According to reflected self-appraisal (part of the 'looking-glass self'), individuals' self-concepts are socially constructed through the judgment of others. Although some might react to negative judgments by nullifying them (e.g., changing themselves, avoiding likely critics) or counterbalancing them (e.g., eliciting positive judgments through other outlets), the more general tendency is for individuals to internalize these social judgments, including negative ones, into their self-concept. (p. 394)

In trying to meet one's role responsibilities an individual might encounter two different types of problems: role strain and role conflict.

Role strain occurs when an individual feels uncomfortable with one or more of the rights or obligations that are attached to a role (Goode, 1960). For example, an individual might like the freedoms and rights of being a college student and the lower expectations for material goods that are associated with this status, but might not like the time commitment to studying that being a student requires. A girl or woman who enjoys being highly competitive might also undergo role strain, as her competitive impulses pull against the traditionally defined role of girls and women, who are expected to assume supportive roles. The role strain represents an internal conflict within individuals that is caused by cultural lag. The old values are not yet fully in line with the material changes that are occurring. Role strain is less for those individuals who have already adjusted their values, though their behavior is often viewed by the surrounding culture as 'deviant'. 
Unlike role strain, which reflects the tensions created by a specific status, role conflict occurs when the responsibilities of one role make it difficult or impossible to fulfill the responsibilities of another. This external conflict is inherent in human existence, especially for ambitious individuals with many statuses, such as parents who work and want to be community leaders as well. Role conflict is a common problem for the female studentathlete. A student's instructors expect her to attend class regularly and to be diligent in her studies. These obligations can sometimes clash with the obligations placed on her as an athlete. In this role, her coaches expect her to spend as much time as possible practicing, exercising, and performing at events. The obligations imposed by these two roles conflict when the student-athlete has to miss classes or assignments because of travel to an athletic event, or she has to miss practice in order to participate in a lab or take an exam. At these times, the woman's role responsibility as an athlete conflicts with her role responsibility as a student.

Visions of beauty and perceptions in general develop through socialization, a lifelong process that starts with the individual's role and status within her family and is reinforced in the educational sector and then wider influences, such as the media. The attitudinal component and the behavioral component are functions of the degree to which the socialization agents - individuals and institutions that help integrate a person into the existing social order - are in harmony. When socialization agents conflict - for example, when a girl receives opposing messages from her teachers and her parents - the girl must resolve the conflicting roles of student and daughter. Merton (1957) comments that a person resolves conflict by either assimilating and accepting the role desired by the broader culture or by rejecting the broader culture and embracing a 'deviant' role.

In an ethnographic study, Hills (2006) describes the process whereby girls learn about the complexities of being athletic and being female as they negotiate their way through adolescence. Lance (2004) notes that women generally feel role conflict as student-athletes much more than men do. However, this does not necessarily extend to money sports, as female basketball players report less conflict than male basketball players.

\subsection{BODY IMAGES: VISUAL REPRESENTATION OF STATUS}

In addition to the role and the associated rights and responsibilities that male and female status entails, an individual's status also has visual representation. In the United States, casual observation of a typical shopping mall or other heavily congested public places reveals many different body 
types and clothing. Extreme appearances are concentrated among teenagers and young adults. Both male and female idealized body images are discernible by their clothing. Adolescent and young women frequently wear very tight and figure-revealing clothing because they regard thin as beautiful. In contrast, adolescent and young men exaggerate their actual or potential large body size with oversized clothing as a large, muscular body is the ideal for them. As people age, the possibility of attaining these idealized body types, thin for women and muscular for men, decreases, and clothing styles become less exaggerated for most. This occurs in part because the status of a young adult differs from the status of an older person.

In this section, I identify the source of the conceptions of the ideal body type in the contemporary United States. The analysis is complicated by wide variations in what is deemed appropriate within a single culture at a moment in time and by changes in social judgments over time. An example of cross-sectional variation comes in differences in the ideal body image among African Americans, Hispanics, and whites. In the United States, the ideal body types for African American and Hispanic women are typically larger than they are for whites. The difference could be caused by a number of factors, including systematic differences in the groups' current and historical social class.

While society's vision of an ideal body image lags behind people's actions, it does evolve over time. A body that contemporary Americans regard as undesirably fat symbolized wealth at the turn of the twentieth century and still does in some African countries today. In addition to changing over time, ideal body images vary by subculture and social class.

The change in beauty standards over time is best captured by the term 'Rubenesque.' Based on the appearance of idealized women in the paintings of the Flemish Baroque painter Peter Paul Rubens, the term has come to mean an attractive but corpulent woman. This standard is perhaps best exemplified in Rubens' masterpiece, The Judgment of Paris. In this painting, three full-figured Greek goddesses vie to be named the most beautiful woman on earth.

In contemporary American society, most people would consider such women to be far too heavy to be considered beautiful. However, at a time when starvation was a common occurrence, extra weight was seen as a desirable feature. As recently as the twentieth-century, American standards of beauty idealized such sex-symbols as Mae West and Marilyn Monroe, who were far heavier than their American counterparts are today. Societies in which malnutrition persists continue to idealize a larger body type. 


\subsection{ATHLETICS, ROLE STRAIN, AND ROLE CONFLICT IN THE UNITED STATES}

In this section, I discuss the relationship between body image and sports participation, and I explain the reactions by girls and women to the ideal body perceived by the broader culture. Research on the impact of sport on girls and young women appears to yield highly contradictory findings. Some studies find that young women who participate in athletics feel better about themselves and their bodies, and - as a result - engage in more constructive behavior, from better eating and study habits to fewer unanticipated pregnancies (Miller et al., 1999; Marten-DiBartolo and Shaffer, 2002; Videon, 2002; and Leeds et al., 2007). Other studies find that athletics lead to negative self-images and self-destructive behaviors, such as disordered eating (for example, anorexia nervosa and bulimia) and excessive exercise (Krane et al., 1997).

One reason for the discrepancy in findings is the difference in the sample these studies use. For the average young woman, sports participation appears to provide a wide array of benefits with relatively few drawbacks. For example, disordered eating among high-school athletes is roughly in line with national averages (Thompson and Sherman, 2010). In contrast, many of the problems associated with sports activity have been found in studies of elite athletes. This dichotomy might result from the greater rewards for success, greater intensity of effort, and greater pressure that exist at the elite level. With less at stake at the elementary- and high-school level of competition, superior performance generally leads to higher selfesteem (Shaffer and Wittes, 2006). Tiggemann and Pickering (1996) also argue that involvement in sports can lead to a positive body image for women, but they find that the percentage of women with a poor body selfimage increases at higher competitive levels.

One important change that occurs as an athlete moves from interscholastic athletic participation to intercollegiate and elite status is the narrowing of her peer group. At the high-school level, sports provide an important mechanism for the individual to share in the broader culture. A recent study of male high-school football players (Steinfeldt and Steinfeldt, 2010) argues that participation in sports has a positive effect on boys, as it solidifies subgroup memberships, a finding supported by O'Neil (2008). Thanks to the success of Title IX, girls can now benefit from such affiliations as well. Today, one of every $2.5 \mathrm{high}$-school girls plays a sport (as opposed to one in 27 prior to Title IX) (Daniels and Leaper, 2006: 875). Participation in sport thus provides a broad-based peer group for high-school-aged girls.

At higher levels of competition, the peer groups become much smaller 
and more homogeneous, with identity increasingly defined by the sport itself. This can be important for the girl's self-image and resulting behavior, as Daniels and Leaper (2006) show that peer acceptance is an important mediator between sport and self-esteem. There is an increasing risk that these mediators could work in a perverse way as athletes move to higher levels of competition. Parsons and Betz (2001) recognize this fluidity, as they find that participation in sports and physical activity is associated with higher scores on body shame subscale, indicating greater internalization of cultural standards of female beauty. However, '[o]verall, research on the relationship of sports participation to eating disorders has been inconclusive, with findings varying by sport, athletic performance level' (p. 210).

The problems faced by female athletes at the elite level depend crucially upon the sport in which they participate. At some risk of oversimplification, one can divide women's and men's sports into 'lean' and 'non-lean' sports. ${ }^{1}$ Lean sports typically involve either weight classes, as in rowing or wrestling, or activities in which added weight presents a disadvantage. The disadvantage could be bio-mechanical, as in distance running. It could also create a subjective disadvantage in judged sports, such as figure skating or gymnastics (Borgen and Corbin, 1987; and Thompson and Sherman, 2010). Women's lean sports are frequently - but not uniformly more overtly feminine than the non-lean sports, with young women often carefully made up and wearing dresses or leotards. These sports therefore involve less role strain than the non-lean sports, as they place women in roles that match their traditional role in society.

The danger facing young women in the lean sports comes not from role strain or conflict but from their complete acceptance of their roles and the images associated with their status. They internalize the pressure placed on them to stay thin. In a nationally representative sample of over 7,000 girls, Crissey and Honea (2006) found that those involved in stereotypically female sports, like gymnastics or ice skating, were more likely to report feeling overweight, to attempt to lose weight, and to use multiple weight-loss strategies than those who were non-athletes. A recent study by Arthur-Cameselle and Quatramoni (2011) finds that attempts to lose weight often resulted from pressure by coaches or parents to stay thin. Because of the surrounding competitive pressure, even something seemingly trivial, such as negative comments about an athlete's weight, can set off disordered eating behavior. Muscat and Long (2008) find that eating disorders are positively related to the number of criticisms girls and young women received about their bodies. Even the uniforms they wear contribute to the pressure to lose weight. These uniforms are often so tight and revealing that, in the words of one track athlete, 'You feel completely naked ... your butt's right there' (Krane et al., 2004: 321). 
Women participating in lean sports are much more likely than the overall population to fall prey to the combination of disordered eating and overly intense exercise that combine to form 'low-energy availability' (LEA). LEA, which is formally defined as caloric intake that is insufficient 'to fuel ... physical activity and support normal bodily processes of growth and development' (Thompson and Sherman, 2010: 21) is one leg of what has been termed the 'Female Athletic Triad', a combination of three interrelated conditions that endanger female athletes. The other two conditions, which stem from LEA, are disrupted menstrual cycle and low bone density. These three disorders are dangerous to the health and - in extreme cases - to the life of the female athlete. Even if these disorders do not cause immediate harm, they can cause severe problems later in life.

Although young women who participate in non-lean sports do not feel the same pressure to lose weight, they are more subject to cultural lag, in which the belief structure of a society fails to keep pace with material changes. In this case, the growing participation of women in sports 'from 294,015 girls in 1971, the year before Title IX came into existence, to 2,784,154 girls in 2001' (Dworkin and Messner, 2002: 348) a figure that has since risen to over 3 million (Anderson, 2012: 49) - has not been accompanied by changes in the perception of how girls or women should behave or look. While Weiss and Barber (1995) find that there is greater social acceptance of female athletes than there was in the 1970s, perceptions continue to lag behind participation. Thus, 'it is not surprising that questions continue to be raised about the potential role conflict that may be experienced by women who, having chosen to participate in the traditionally defined male domain of competitive athletics, must balance the roles of female and of athlete' (Goldberg and Chandler, 1991: 213).

According to Kornblum (2011), girls fill a particular role in society. They are expected to be compassionate and understanding, to be cooperative rather than competitive, to assume supportive as opposed to leadership roles, and to vicariously enjoy the success of the males in their environment. In effect, they are expected to be cheerleaders rather than athletes. Gender distinctions are reinforced on a daily basis. For example, in a content analysis of magazine advertisements, O'Barr (2006: 163) found, 'Masculine images typically convey power, strength, virility, athleticism, and competitiveness whereas feminine images show beauty, submissiveness, nurturance, and cooperation'. Such behaviors conflict with the independence and assertiveness athletes need to be successful. In the words of one athlete, 'You lose all femininity when you put on a hockey uniform' (Krane et al., 2004: 319).

The behavioral conflict is reinforced by differences between the ideal body type for most non-lean sports and the societal ideal of the thin 
woman described above. Young women recognize the conflict between the requirements of their sport and 'hegemonic femininity'. Female athletes have coped with this conflict in several ways. One particularly noticeable coping mechanism has been an effort to compensate for their body type and behaviors by overtly feminine displays during competition. As a result, one often sees women paying particular attention to their hair and make-up before competing in track, hockey, or even boxing (Krane et al., 2004; Kauer and Kane, 2006).

Some researchers specifically cite the conflict an athlete faces as being between having the body shape required for athletic success and having the ideal 'White' or 'Western' body. This argument implicitly assumes that there is no clash of ideals in other cultures (see Krane et al., 2004: 315; and Kauer and Krane, 2006: 44), but the problem appears to be universal. In the words of Amantle Montsho, Botswana's first world-class woman runner, 'Women in Botswana don't like sports.... They don't like the look of muscles' (Pilon, 2012).

We no longer live in an era when women confront scientific 'evidence' that intense exercise will prevent them from bearing children or turn them into men (Millar, 1999), but cultural lag can make young women question their female identity. Female athletes recognize that their participation in sports, particularly in such non-lean sports as softball and basketball, causes them to be perceived as 'jock girls' or lesbians (Kauer and Krane, 2006). Some (for example, Wright and Clarke, 1999) regard the stigmatization of lesbianism as a broader assault on women's sports. They claim that trivializing and sexualizing women's sport is a way to deny power to women who participate in non-traditional sports.

Women in other cultures, however, face more than just trivialization. For example, Longman (2011) points out that officials and the general public sometimes question the sexuality of women athletes. In the run-up to the 2011 Women's World Cup, Nigerian officials accused Equatorial Guinea of using men on their women's soccer team 'because of their supposed masculine appearance'. It has also led to an extreme fear of lesbianism on women's teams. This fear has caused players of suspect sexuality to be dismissed from the Nigerian team and, in South Africa, to incidents of physical and sexual violence against women soccer players.

\subsection{BARRIERS IN ISLAMIC CULTURE}

While the conflict between athleticism and femininity is present everywhere, it is most pronounced in Muslim cultures. In addition, Muslim women often face explicit as well as implicit pressure. While sociological 
analyses of sport often cite the implicit pressure of 'hegemonic femininity' on women in Western cultures, women in Muslim cultures or subcultures often face explicit limitations placed on them by family, nation, and mosque. In some instances, the state has imposed restrictions on female athletes. For example, Saudi Arabia agreed - almost literally at the last minute - to send two women to the 2012 Summer Olympics. This about-face came only after extraordinary pressure from the International Olympic Committee, which included a possible ban of its male athletes (Cesari, 2012). Saudi Arabia's policy goes beyond the Olympics. It proscribes physical education for girls in public schools and has even refused to let women participate in the Islamic Women's Games (ibid.; Clarey, 2012). Even in the absence of official restriction - often in relatively permissive Western societies - Muslim women are still subject to considerable pressure. This pressure often comes from the household, as parents place limits on their children, particularly their daughters, to stay within the religious and cultural norms of the subgroup and not to take on the identity of the broader society (Kay, 2006; Walseth, 2006).

Islam places no restriction on physical activity by women per se. In fact, many believe that Islam encourages it. In a series of interviews with female Egyptian university students, Walseth and Fasting (2003) find that even deeply observant Muslim women believe that 'Islam encourages women to participate in sport' and that sport is 'a positive activity for them' (p.53). In a popular hadith (saying of the Prophet Mohammed), the Prophet's youngest wife, Aisha, competes with him in a race and wins (Nakamura, 2002: 22). Many religious Muslims conclude from this hadith that 'taking care of the body through exercise is ... an Islamic duty' (Kay, 2006: 358).

The barriers to sports participation arise from two conditions that strict interpretations of Islam might place on female athletes. Both of these conditions stem from the emphasis on modesty and the proscription of actions that could arouse the opposite sex. It is no surprise that some Saudi bloggers have referred to the country's two female participants - both of whom were completely covered (in one instance over the objections of the International Judo Federation) - as prostitutes who 'do not represent the chaste Muslim women' (Council on Foreign Relations, 2012). Although similar provisions of modesty apply to men's dress and behavior, men typically ignore such restrictions without arousing comment.

Some Muslim women are willing - or permitted - to compete publicly but only if they dress appropriately. Such dress ranges from the hijab, which covers the head, to the krimar, which covers the head, neck, and torso, to the full face and body covering of the nikab. This attire makes it increasingly difficult for women to participate in competitive sports, as 
even the hijab severely handicaps women who wish to participate in sports involving motion, such as track or gymnastics (Kay, 2006: 359).

For some, even modest attire is not enough. In the words of one young woman, 'Running is not $\mathrm{OK}$ in front of men. You should only run if there is a danger. Your body shakes when you run, and men can be attracted' (Walseth and Fasting, 2003: 54). For such people, women can participate in sport only if there is complete separation of the sexes. Thus, only the opening ceremonies of the Women's Islamic Games are open to the general public. All other activities take place 'in a completely female environment allowing women, who would not normally access similar competition due to religious and cultural sensitivities, to experience the thrill and privilege of representing their country at high-level competition' (Muslim Women's Sports Foundation, 2012).

Cultural lag in Muslim countries, such as Saudi Arabia and Iran, is strongly pronounced. The values of the ruling classes are purposefully held constant while the material culture surrounding them has changed. Muslim women are supposed to have no public body image at all. Many women are experiencing role strain as they struggle to adapt to the expectations placed on them. While this strain is most pronounced in the Muslim communities in Western cultures (Walseth, 2006), changes may soon move to majority-Muslim nations. The Muslim world is experiencing a revolution (the 'Arab Spring'), part of which might redefine the status of women in society and the accompanying roles they will take on.

\subsection{CONCLUSION}

This chapter presents a framework within which to analyze and understand the sports participation of women and the associated behavior of women athletes. People's behavior is influenced by the roles that follow from their statuses. Cultural lag sometimes presents an outdated set of behaviors associated with specific roles. For the individual, this leads to the internal struggles of role strain, which occur when the behavior associated with their roles no longer fully corresponds to the surrounding material culture. Role conflict occurs when a person holds multiple statuses that imply different rights and responsibilities.

The body image is a visual representation of the status of women. The ideal image changes over time and can differ among the many subgroups of society. The adoption of the image by women comes in several stages and its success depends on the harmony between different socializing agents.

In Western society, some women do not suffer from role strain but 
from the opposite problem of trying too hard to conform to the roles and statuses that confront them. Close identification with the thin ideal women can lead to many problems. Especially in lean sports, where lower weight improves performance, it can set off eating disorders, excessive exercise, and other behaviors that lead to low energy availability. The problem in non-lean sports is a less dangerous role conflict of woman versus athlete. Many athletes respond by exaggerating their body image to compensate for their athleticism. This general problem of conflict between the ideal image and athleticism seems to be universal.

The precarious position of women athletes in the Muslim world is not necessarily a function of religious doctrine. There is nothing intrinsically hostile to women sports participation in Islam, but the current status of women in the Muslim world is a result of cultural lag. The strict interpretation of Islam is in conflict with changing material culture and creates both role strain and role conflict for women in this culture.

\section{NOTE}

1. While I focus specifically on women, men are also subject to many of the same pressures. There are many accounts of wrestlers or jockeys who have become ill or even died as a result of attempts to lose weight. See, for example, Thompson and Sherman (2010).

\section{REFERENCES}

Anderson, Kelli (2012), 'Nine for IX', Sports Illustrated, May 7: 49.

Arthur-Cameselle, Jessyca and Paula Quatramoni (2011), 'Factors Related to the Onset of Eating Disorders Reported by Female Collegiate Athletes', Sport Psychologist, 25(1), March: 1-17.

Borgen, Jorunn and Charles Corbin (1987), 'Eating Disorders among Female Athletes', Physician and Sports Medicine, 15(2), February: 88-95.

Cesari, Jocelyne (2012), 'Saudi Women Going to Games Is a Sham', CNN Opinion, online at: http://www.cnn.com/2012/08/01/opinion/cesari-saudi-women-sports/index.html (accessed August 1, 2012).

Clarey, Christopher (2012), 'Ban Urged on Saudi Arabia over Discrimination', New York Times, February 15, online at: http://www.nytimes.com/2012/02/16/sports/olympics/ olympic-ban-on-saudi-arabia-is-urged-over-lack-of-female-athletes.html (accessed May 24, 2012).

Cooley, Charles (1902), Human Nature and the Social Order, New York: Scribner's.

Council on Foreign Relations (2012), 'The Symbolic Victories of Saudi Arabia's Female Olympians', The Atlantic, online at: http://www.theatlantic.com/international/ archive/2012/08/the-symbolic-victories-of-saudi-arabias-female-olympians/260998/ (accessed August 11, 2012).

Crissey, Sara and Joy Honea (2006), 'The Relationship between Athletic Participation and Perceptions of Body Size and Weight Control in Adolescent Girls: The Role of Sport Type', Sociology and Sport Journal, 23(3), September: 248-72.

Crosnoe, Robert and Chandra Muller (2004), 'Body Mass Index, Academic Achievement, 
and School Context: Examining the Educational Experiences of Adolescents at Risk of Obesity', Journal of Health and Social Behavior, 45(4), December: 393-407.

Daniels, Elizabeth and Campbell Leaper (2006), 'A Longitudinal Investigation of Sport Participation, Peer Acceptance, and Self-esteem among Adolescent Girls and Boys', Sex Roles, 55(11-12), December: 875-80.

Dworkin, Shari and Michael Messner (2002), 'Gender Relations in Sports', Sociological Perspectives, 45(4), Winter: 347-53.

Friedman, Thomas (2000), The Lexus and the Olive Tree, New York: Farrar, Straus, \& Giroux.

Garfinkel, Harold (1984), Studies in Ethnomethodology, Cambridge: Cambridge University Press.

Goldberg, Alan and Timothy Chandler (1991), 'Sport Participation among Adolescent Girls: Role Conflict or Multiple Roles?', Sex Roles, 25(3/4), August: 213-24.

Goode, William (1960), 'A theory of role strain', American Sociological Review, 25(4), August: $483-96$.

Hills, Laura (2006), 'Playing the Field(s): An Exploration of Change, Conformity, and Conflict in Girls' Understandings of Gendered Physicality in Physical Education', Gender and Education, 18(5), September: 539-56.

Kauer, Kerrie J. and Vikki Krane (2006), "Scary Dykes" and "Feminine Queens": Stereotypes and Female Collegiate Athletes', Women in Sport and Physical Activity Journal, 15(1), Spring: 42-55.

Kay, Tess (2006), 'Daughters of Islam: Family Influences on Muslim Young Women's Participation in Sport', International Review for the Sociology of Sport, 41(3-4), December: $357-73$.

Kornblum, W. (2011), Sociology in a Changing World, Belmont, CA: Wadsworth/Cenage Learning.

Krane, Vikki, Precilla Choi, Shannon Baird, Christine Aimar and Kerrie Kauer (2004), 'Living the Paradox: Female Athletes Negotiate Femininity and Muscularity', Sex Roles, 50(5-6), March: 315-29.

Krane, Vikki, Christy Greenleaf and Jeannine Snow (1997), 'Reaching for the Gold and the Price of Glory: A Motivational Case Study of an Elite Gymnast', The Sport Psychologist, 11(1), March: 53-71.

Lance, Larry (2004), 'Gender Differences in Perceived Role Conflict Among University Student-Athletes', College Student Journal, 38(2), June: 179-90.

Leeds, Michael, Cristen Miller and Judith Stull (2007), 'Interscholastic Athletics and Investment in Human Capital', Social Science Quarterly, 88(3), September: 729-44.

Longman, Jere (2011), 'Homophobia Still an Obstacle in African Women's Soccer', New York Times, June 23: B11.

Marten-DiBartolo, Patricia and Carey Shaffer (2002), 'A Comparison of Female College Athletes and Nonathletes: Eating Disorder Symptomatology and Psychological Well-being', Journal of Sport and Exercise Psychology, 24(1), March: 33-41.

Maynard, Michelene (2011), 'The Kicking Queen', New York Times, October 4: B13.

Merton, Robert (1957), Social Theory and Social Structure, Glencoe, IL: Free Press.

Millar, Stuart (1999), 'How the Bearded Lady Spoiled Sport', The Guardian, March 30, online at: http://www.guardian.co.uk/uk/1999/mar/31/stuartmillar (accessed May 24, 2012).

Miller, Kathleen, Don Sabo, Michael Farrell, Grace Barnes and Merrill Melnick (1999), 'Sports, Sexual Behavior, Contraceptive Use, and Pregnancy among Female and Male High School Students: Testing Cultural Resource Theory', Sociology of Sport Journal, 16(4), December: 366-87.

Muscat, Anne and Bonita Long (2008), 'Critical Comments about Body Shape and Weight: Disordered Eating of Female Athletes and Sport Participation', Journal of Applied Sport Psychology, 20(1), January: 1-24.

Muslim Women's Sports Foundation (2012), Islamic Games, online at: http://www.mwsf.org. uk/islamic_games.html (accessed May 25, 2012). 
Nakamura, Yuka (2002), 'Beyond the Hijab: Female Muslims and Physical Activity', Women's Sport and Physical Activity Journal, 11(2), Fall: 21-48.

O'Barr, William (2006), 'Representations of Masculinity and Feminity in Advertisements', Advertising and Society Review, 7(2), online at http://muse.jhu.edu/journals/asr/indexb. html (accessed September 14, 2006).

O’Neil, James (2008), 'Summarizing 25 Years of Research on Men's Gender Role Conflict Using the Gender Role Conflict Scale: New Research Paradigms and Clinical Implications, The Counseling Psychologist, 36(3), May: 358-445.

Ogburn, William (1922), Social Change with Respect to Cultural and Original Nature, Oxford: Delta Books.

Parsons, Elizabeth and Nancy Betz (2001), 'The Relationship of Participation in Sports and Physical Activity to Body Objectification, Instrumentality, and Locus of Control among Young Women', Psychology of Women Quarterly, 25(3), September: 209-22.

Pilon, Mary (2012), 'The Footprints on a Path to Gold', New York Times, April 22, online at: http:/www.nytimes.com/2012/04/22/sports/olympics/amantle-montsho-overcomesobstacles-to-become-a-track-champion.html?pagewanted=all (accessed May 12, 2012).

Shaffer, David and Erin Wittes (2006), 'Women's Precollege Sports Participation, Enjoyment of Sports, and Self-esteem', Sex Roles, 55(3-4), February: 225-32.

Steinfeldt, Jesse and M. Clint Steinfeldt (2010), 'Gender Role Conflict, Athletic Identity, and Help-seeking among High School Football Players', Journal of Applied Sport Psychology, 22(3), July: 262-73.

Thompson, Ron and Roberta Trattner Sherman (2010), Eating Disorders in Sport, New York: Routledge.

Tiggemann, Marika and Amanda Pickering (1996), 'Role of Television in Adolescent Women's Body Dissatisfaction and Drive For Thinness', International Journal of Eating Disorders, 20(2), September: 418-31.

Videon, Tami (2002), 'Who Plays and Who Benefits: Gender, Interscholastic Athletics, and Academic Outcomes', Sociological Perspectives, 45(4), Winter: 415-44.

Walseth, Kristin (2006), 'Young Muslim Women and Sport', Leisure Studies, 25(1), August: 75-94.

Walseth, Kristin and Kari Fasting (2003), 'Islam's View on Physical Activity and Sport: Egyptian Women Interpreting Islam', International Review for the Sociology of Sport, 38(1), March: 45-59.

Weiss, Maureen and Heather Barber (1995), 'Socialization Influences of Collegiate Female Athletes: A Tale of Two Decades', Sex Roles, 33(1/2), July: 129-40.

Woodard, James (1934), 'Critical Notes on the Culture Lag Concept', Social Forces, 12(3), March: 388-98.

Wright, Jan and Gill Clarke (1999), 'Sport, the Media and the Construction of Compulsory Heterosexuality', International Review for the Sociology of Sport, 34(3), September: $227-43$. 